\title{
Comparative process architectures in two higher education institutions
}

\author{
Ian Beeson and Stewart Green* \\ Department of Computer Science and Creative Technologies, \\ University of the West of England, \\ Coldharbour Lane, Bristol, BS16 1QY, UK \\ E-mail: ian2.beeson@uwe.ac.uk \\ E-mail: stewart.green@uwe.ac.uk \\ *Corresponding author

\section{Richard Kamm} \\ School of Management, \\ University of Bath, \\ Claverton Down, Bath, BA2 7AY, UK \\ E-mail: r.m.kamm@bath.ac.uk
}

\begin{abstract}
Enterprises are increasingly organising their activities and IT support around key business processes. These processes and their interrelationships may be identified in a process architecture. Ould (2005) claims that the Riva method identifies the process architecture that an organisation should have, and asserts that organisations in the same business have the same process architecture. This assertion is not self-evidently true, and it has not been corroborated by the literature. But it is an important claim: if true, then process architectures could be reused either for new process development, or for appraising an organisation's existing architecture. We assessed the assertion by comparing the process architectures produced by applying Riva to two higher education institutions. The results partially support the view that an essential process architecture underpins higher education institutions, and also that for regulated business domains the optimal process architecture may be one based upon designed as well as essential business entities. The conclusion is that process architecture reuse, with its attendant potential savings of time and money, is worth investigating further, even though the extent to which the invariant assertion is testable may not be clear yet.
\end{abstract}

Keywords: business process architecture; enterprise architecture; higher education; Riva; business process architecture reuse; organisational design; business processes; higher education institution.

Reference to this paper should be made as follows: Beeson, I., Green, S. and Kamm, R. (2013) 'Comparative process architectures in two higher education institutions', Int. J. Organisational Design and Engineering, Vol. 3, No. 1, pp.35-66.

Biographical notes: Ian Beeson, after an early career (1969-1982) which included working as a Programmer and Systems Analyst for the national postal/telecommunication organisation and for a local authority, then lectured in information systems for close to 30 years, first at Manchester Polytechnic and then at the University of the West of England, until his retirement in 2011. 
His qualifications are in social anthropology and computer science and his central research interests are focused in the philosophy of information technology, social informatics, and the scope and limits of systems modelling.

Stewart Green is the Programme Leader for both Computer Science and Software Engineering in the Department of Computer Science and Creative Technologies, University of the West of England. He teaches requirements engineering and researches business process architectures. He is a registered assessor for the British Computer Society. He obtained his MSc in Foundations of Advanced Information Technology and a $\mathrm{PhD}$ in Computer Science, both from Imperial College, London. Prior to this, he worked for 12 years in the IT industry for ICL, British Aerospace, and Prime Computers. His first degree, BSc (Hons) Psychology, was obtained from the Hatfield Polytechnic.

Richard Kamm is the Head of Learning and Teaching Quality and a member of the Information Systems teaching staff at the School of Management, University of Bath. He has published on business process modelling and on the wider context of information systems in organisations. He has also worked for the Quality Assurance Agency, the body for higher education standards in the UK, on the national code of practice for universities.

This paper is a revised and expanded version of a paper entitled 'Process architectures in higher education' presented at UKAIS, St Anne's College, Oxford, 2009.

\section{Introduction}

In order to achieve key objectives more efficiently and effectively, many organisations today are adopting a process oriented perspective on their activities. This usually involves the identification, analysis and modelling of important organisation processes, and the provision of supporting computer-based systems. Unfortunately, it seems unlikely that such piecemeal development leads to the coherent set of interrelated processes that an organisation needs in order to address its strategy and meet its objectives. To address this problem, Harmon (2003) recommends that a process architecture should first be identified and modelled before individual processes are selected, modelled and supported by IT. Such a process architecture can then be used to identify both the processes to develop, and the relationships between them.

Process architecture is a growing area in computing. Proposals for generic information systems architectures date back to Zachman's (1987) framework. Other high-level frameworks include The Open Group Architecture Framework (TOGAF) (The Open Group, 2002), and the Object Management Group (OMG)'s model-driven architecture (Frankel, 2003). Lankhorst et al. (2005) provide a good overview of the state of the art in enterprise architecture frameworks, methods and languages. A set of generic models of typical business activities, complemented by a repository of particular cases, has been compiled, put into an organisational framework and recorded in the MIT Process Handbook (Malone et al., 2003). These high-level frameworks and categorisation exercises have been very important in establishing the field of process or enterprise architecture and providing blueprints for business process design in organisations. 
And again, within the literature on business process change, there is general acceptance of the idea of reusing process architectures as a principle. A variety of writers on business process reengineering or redesign stress the importance of developing in the operators of a process a sense of how their work connects to the other business processes in the organisation (Grover et al., 2000; Hammer, 1996; Kettinger et al., 1997). Process redesign projects require a holistic perspective and its effective communication if they are to produce lasting beneficial change. The idea of a process architecture makes such a perspective specific to the organisational situation while creating a link to the analysis of individual processes.

However, once process architecture for a given type of organisation exists, questions are raised about patterns of processes and the extent to which they can be re-used or standardised. In principle, if reuse is feasible, there are advantages to be gained: organisations would be able to implement changes based not only on designs of individual processes but on combinations of processes which have already been shown to be robust. The concentration on reuse in process modelling to date, however, has been on individual processes, most notably Malone et al. (2003). A focus on the reuse of process architectures is relatively new. One example of an existing scheme where a process architecture has been provided both to guide the development of processes in new organisations and to appraise the provision of processes in existing organisations is the eBusiness Telecom Operations Map (eTom).

However, this is a process architecture for just one specific business domain: telecommunications. The process architecture method we examine here (see below) provides ideas and notation for identifying and modelling the relevant processes and their interrelationships for any business domain.

The implications of process architecture reuse could be significant for information systems design and implementation. Efforts to introduce new information systems in the type of organisation examined here, higher education institutions, have been affected by inappropriate assumptions about the applicability of software designed in one context to the same process in a different setting (Fowler and Gilfillan, 2003). The best known example is the implementation of Financial Information Systems at Cambridge University, where a package developed for universities in the USA proved inherently unsuitable for the different structure and culture of that institution (Finkelstein and Shattock, 2001).

While a number of process architecture methods, in addition to the ones already mentioned, have been proposed (Kavakli and Loucopoulos, 1999; Kawalek and Snowdon, 2003; Lunn et al., 2003), the focus of this paper is upon Riva (Ould, 2005), a method which has received attention in the UK. Riva derives an organisation's process architecture from the key entities that are the organisation's subject matter. For example, for the domain of higher education, entities might include programme, module and student; and a corresponding Riva process architecture would be derived from these. Ould (2005, p.171) makes the strong assertion that "a Riva process architecture is an invariant for an organization that stays in the same business": in other words, two organisations in the same business will have the same process architecture.

Although the Riva method has been published to encourage its greater take up, few studies have been reported that assess the strong assertion just noted. One study, undertaken in a faculty at the University of the West of England (UWE), applied Riva to the faculty administration organisation (Green and Ould, 2005). In order to assess Ould's assertion, and thus the potential for reuse of process architectures, as well as the ease with 
which Riva can be applied, the work in this paper, discussed herein, extends that early study by applying Riva to the development and deployment of undergraduate and postgraduate programmes (i.e., awards or courses) that belonged in 2006 to two different higher education institutions: the faculty of Computing, Engineering and Mathematical Sciences (CEMS) at the UWE, and to the School of Management at the University of Bath (UB). The main question that was addressed through this research was:

- Would the same essential process architecture be found in two organisations that were ostensibly in the same business, but manifestly had many important differences?

An answer to this question would allow us to suggest how much support there was for Ould's assertion that a Riva process architecture is invariant for the same types of organisation and also to what extent reuse of a process architecture for higher education was a possibility. As a by-product of addressing the research question, we also hoped to discover issues and difficulties associated with applying the documented Riva method to real world organisations.

To address the research question, the researchers carried out two modelling activities and compared the results with each other. The two cases chosen were the faculty of CEMS at the UOW, and the School of Management at the UB. These two higher education organisations were chosen because, although they had significant differences, they were considered to be in the same business. Additionally, two of the researchers were familiar with the UOW, while the third was familiar with the UB. The two sets of researchers at their respective institutions independently both applied the Riva process architecture method, and also obtained required institutional characterisation data. The models that were produced as outcomes of the application of Riva were compared and discussed by all three researchers together. However, as described in Section 5, at the point when one of the key models was reconsidered, this was done first by the researchers at the UOW, who then validated the results with the colleague at the UB. The final results of the comparison exercise were discussed by the three researchers together and the conclusions agreed to, also together.

The paper compares two analyses of situations using the same technique in order to generate discussion of that technique and a claim about its general principles. The research methodology is therefore a form of exploratory case study research (Yin, 2009) in which the unit of analysis is the comparison which draws on material from two situations: a single case study with two sources of data. The discussion of the findings contains suggestions for the differences and similarities found in the modelling exercises as a way of encouraging development of the Riva techniques and their application in other types of situation.

This paper is structured as follows. Section 2 provides a tutorial introduction to Riva. Section 3 compares and contrasts the cultures and teaching styles of the two organisations involved. The process architectures resulting from an initial application of Riva within each organisation are depicted and compared in Section 4. The authors judged these models to be relatively complex, and an attempt to simplify them led us back to Ould's (2005) work to reconsider how Riva should be applied; the results of this rethink are presented in Section 5. Section 6 presents and discusses the results of re-applying Riva. The outcomes of all of these endeavours are discussed in Section 7, which reviews the extent of the similarity between the two institutions' process architectures; it also both discusses the extent to which Ould's invariant assertion can be assessed precisely, and 
notes that an optimally reusable process architecture might be better based upon both essential and designed business entities (DBEs). Section 8 summarises the results of this work, discusses some potential problems and limitations, and outlines possible future work. Appendices 1 to 7 depict process architectures produced in the case studies; Appendix 8 discusses key similarities and differences between the two institutions; and Appendix 9 provides a glossary of abbreviations.

\section{The Riva approach to process architecture}

\subsection{Key concepts}

The fundamental concept of the Riva approach is that an organisation's process architecture can be derived from the essential business entities (EBEs) that are its subject matter, i.e. the entities that characterise the business. For example, because an insurance company is characterised by entities such as customer, policy, and claim, then the process architecture for this organisation should be based directly on these EBEs. And it is assumed axiomatically that exactly this process architecture will be found for any insurance company; there may be differences from organisation to organisation over the way processes comprising the architecture have evolved or been designed, but the process architecture itself, i.e., the identified processes and their interrelationships, will be the same.

The Riva method assumes that a process architecture will interrelate three distinct kinds of processes:

- $\quad$ case processes $(\mathrm{CP})$

- $\quad$ case management processes (CMP)

- $\quad$ case strategy processes (CSP).

A particular CP specifies the standard way that each instance of this kind of case is handled within an organisation. There will be a distinct $\mathrm{CP}^{1}$ for each distinct $\mathrm{EBE}$ characterising the organisation. EBEs whose lifetime is the responsibility of the organisation under consideration are called Units of Works (UOWs). So there will be a distinct CP associated with each distinct UOW. As an example of a CP, consider a new claim made by a customer arriving at the insurance company. Here, the UOW is Claim event and there will be a standard CP for handling claims; each new claim results in a new instance of this CP being instantiated.

A particular CMP manages the flow of instances of its associated CPs. In particular, the single instance of a CMP receives requests for, schedules and then activates each instance of its corresponding CP; it also monitors the performance of each associated CP instance and, depending upon performance, may perform other activities such as stopping an associated CP instance or allocating more resources to it. As an example of a CMP, consider the assessment of each claim against a policy. Here the UOW is Claim assessment event. For each request for a claim assessment, the CMP for claim assessments will schedule a $\mathrm{CP}$ instance to handle that claim assessment, monitor its progress, and so on.

So far, we have indicated that each UOW is associated with a CP, CMP (and $\mathrm{CSP}$ - see below). However, the great value of a process architecture is that it shows how 
the CPs, CMPs, and CSPs for all of an organisation's UOWs are interrelated. These interrelationships are derived from the dynamic relationships that exist among an organisation's UOWs. As an example, consider claim events and the claim assessments necessitated by such events. Here both the claim event and the claim assessment events are UOWs, and a claim event UOW is deemed to generate (or lead to) one or more claim assessment events UOWs. This situation is modelled in Figure 1, where the cardinality of the association is denoted in the conventional way: here 1 to $1 . .^{*}$, meaning one claim event is associated with one or more claim assessment events.

Figure 1 Fragment of a UOW diagram

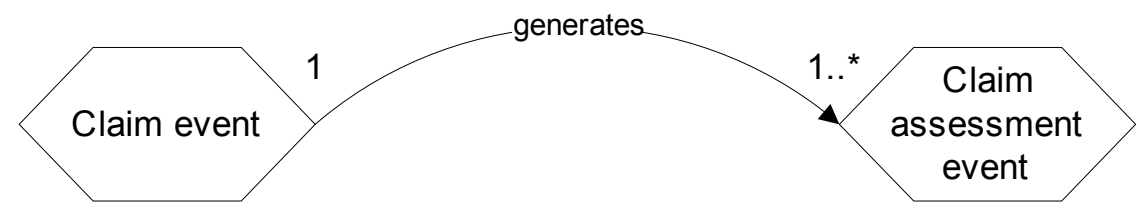

Intuitively, one can now see how a fragment of a corresponding process architecture is derived from the dynamic relationships between these two UOWs. At some point during the lifetime of an instance of the claim event $\mathrm{CP}$, it requests the instance of the CMP for claim assessment events to schedule the assessment of the claim associated with this claim event. In its turn, this CMP instance instantiates a CP to handle the claim assessment event. And this latter $\mathrm{CP}$ eventually delivers an assessed claim to the instance of the claim event CP. This situation is modelled in Figure 2.

Figure 2 Fragment of a process architecture diagram (see online version for colours)

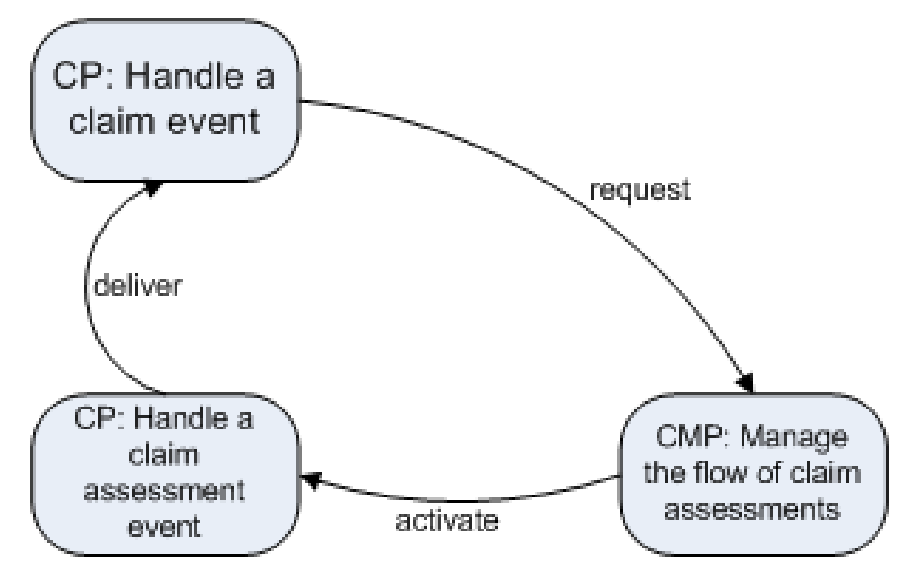

The situation is slightly more complicated than has been presented here because two distinct kinds of dynamic relationships - service and task-force - are possible between UOWs. However, this topic is beyond the scope of this paper, but the interested reader is referred to (Ould, 2005, chapter 5).

Finally, CSPs take a strategic view of UOWs. Ould (2005, p.166) makes it clear that "a CSP has its CP and CMP as its subject matter". The CSP is concerned with questions like: What is happening inside the business that will affect each UOW? How are such 
changes dealt with? What is the impact of rates or volumes of UOWs changing? Can the $\mathrm{CP}$ and/or the CMP be improved? And so on (Ould, 2005). CSPs are characteristically multi-threaded: some are event-driven - responding to internal or external phenomena - others are calendar driven. However, in Riva, the CSP concept is not as developed as CP and CMP concepts, with only three pages from the book (pp.166-167, p.305) devoted to their presentation. In addition, CSPs do not feature in any of Ould's examples of process architectures. For these reasons, we do not consider them further in this paper. Clearly a more elaborate treatment of CSPs within Riva is an area for future work.

This conceptual framework is further complicated through recognition that an organisation may have particular processes because it has chosen to do some things in particular ways; these relate to the 'designed' rather than the 'essential' business entities and associated UOWs. DBEs - and corresponding designed units of work (DUOWs) - are not essential in the same way that EBEs are; they are normally a mechanism for achieving something chosen from a number of alternative mechanisms for achieving the same thing. The role of DBEs, although perhaps underemphasised in Ould's work, is explored in the work presented here.

\subsection{The Riva method}

Broadly, the Riva method for identifying an organisation's process architecture comprises the following sequence of activities:

1 Determine the boundary of the organisation under consideration. This is a crucial step, as the placement of the boundary determines the set of UOWs for an organisation. 'Boundary' here may refer to something that bounds the whole of an organisation, or a part of it.

2 Brainstorm the subject matter of the organisation to identify its EBEs.

3 Identify those EBEs that have a lifetime which the selected organisation must handle; these are called UOWs.

4 Create a UOW diagram that shows the dynamic relationships between UOWs that pertain when one UOW generates (or calls for, or demands, or activates, or requires) another.

5 For each UOW, hypothesise that there will be in the process architecture a $\mathrm{CP}$ that deals with a single instance of the UOW, a CMP that deals with the flow of instances, and a CSP that determines the future strategy for both the CPs and CMPs.

6 Transform the UOW diagram into a corresponding first-cut process architecture by turning the relationships between UOWs into relationships between the corresponding CPs and CMPs.

7 Apply the heuristics identified by Ould (2005, pp.185-194) to the first-cut process architecture in order to produce a reduced architecture, denoted the second-cut process architecture.

At this point, the process architecture based upon EBEs has been created. It is the most fundamental architecture within Riva because it is based upon an organisation's EBEs. 
8 Steps two to seven may now be repeated, this time also considering DBEs, and corresponding DUOWs, as well as EBEs. The resulting architecture will be less generic, but closer to the actual organisation under consideration.

\section{Institutional profiles}

The two institutions, the UB and the UWE, whose process architectures we compared in 2006-2007, are each characterised below. Table 1 records the main similarities between the two, and Table 2 the main differences. Appendix 8 provides a comprehensive presentation and discussion of these points of similarity and difference.

These two institutions were used for comparison because of the possibility that the relationships between processes were sufficiently different to make the same process architecture difficult to achieve. For the area of activity examined, the management of taught programmes, the two university departments were in what Ould would describe as the same business: producing degree-level education and awarding the qualifications based on the achievements of their students. They also operated within a similar national regulatory context and on a similar scale. However, as is recorded below and explained in Appendix 8, the way in which significant operational decisions were made differs, and this may be reflected in the relevant process architectures.

Table 1 Similarities between the two institutions (2006/2007)

\begin{tabular}{lcc}
\hline Similarity & University of Bath & University of the West of England \\
\hline Educational activities & $\begin{array}{c}\text { Undergraduate and post } \\
\text { graduate teaching and research }\end{array}$ & $\begin{array}{c}\text { Undergraduate and post graduate } \\
\text { teaching and research }\end{array}$ \\
Staff numbers (academic, & 140 & 132 \\
administrative and support) & 204 & 332 \\
Modules offered & 1996 & 2245 \\
Student registrations & 1662 & 1924 \\
Full time equivalent student & & \\
numbers & & \\
\hline
\end{tabular}

Table 2 Differences between the two institutions

\begin{tabular}{|c|c|c|}
\hline Difference & University of Bath & University of the West of England \\
\hline Institutional income source & More from research & More from teaching \\
\hline $\begin{array}{l}\text { Faculty areas of } \\
\text { responsibility }\end{array}$ & Only two official roles & Highly articulated set of roles \\
\hline $\begin{array}{l}\text { Programme vs. module } \\
\text { focus }\end{array}$ & Programme-centric & Module-centric \\
\hline $\begin{array}{l}\text { Module responsibility and } \\
\text { management }\end{array}$ & Individual member of staff & Owning Field \\
\hline Module failure consequence & Repeat whole year & Retake only failed modules \\
\hline Module credit awarded by: & $\begin{array}{l}\text { Department hosting the } \\
\text { programme }\end{array}$ & Department hosting the module \\
\hline
\end{tabular}


The description of the two institutions in terms of their structures and procedures set the terms of the comparison of their process architectures, when defined more formally through the use of the Riva methodology. There were clearly activities in common, but also differences in the way in which important operational decisions were made: on what to teach, on whether to accept appeals or extenuating circumstances claims, and on the award to students of credit and degree-level qualifications. The modelling exercise that follows investigates the extent to which these differences were reflected in process architecture. This, in turn, provides an indication of the limits to consistency in the links between processes, i.e. of the ease of difficulty of ensuring reusability of the process architecture.

\section{First attempts at process architectures}

Riva was applied to the two organisations as they existed in 2006-2007. One researcher applied Riva at the UB. The other two researchers applied Riva at the UWE. The next sections first present, and then compare, the results of these applications of Riva. But because a process architecture can be derived in a fairly mechanical way from a UOW diagram, only the latter are included in the body of the text; however, for completeness, process architectures are included in the appendices.

\subsection{School of Management in the UB}

Figure 3 and Appendix 1 illustrate the formal side of programme management in the UB's School of Management at that time. The important points to highlight, linked to the previous comparison of the two academic institutions, are:

Units (the equivalent of the UWE's 'modules') generate unit runs, which generate Assessment Specifications and boards of examiners (units). The board of examiners for Units is there to ratify the marks that students are awarded, but not to award credit.

Degree Schemes (the equivalent of UWE 'programmes') generate degree scheme runs which generate degree scheme cohorts which generate boards of examiners (programmes). The board of examiners for programmes cannot change the marks that students have been awarded, but does award credit and handles all of the mitigating (extenuating) circumstances claims. Students may not appeal against their mark, but can appeal against a decision about progression or the award of qualifications.

External examiners are in an ambiguous position, in that they are asked to provide feedback on the decisions of boards of examiners for units, but are required to attend the boards of examiners for programmes. Their reports are written after attendance at the latter and they therefore have no direct influence on the marks awarded.

Units themselves can be generated by degree schemes but can also be generated by staff allocation. If a new member of staff arrives, with particular research interests, they must be allocated teaching duties. This allocation will often involve the creation of a new unit around their research interests. Typically, compulsory units would be generated by Degree Schemes, while units which are highly specific to staff members' research interests would be advanced level options. 
Figure 3 UOW diagram (UB) (see online version for colours)

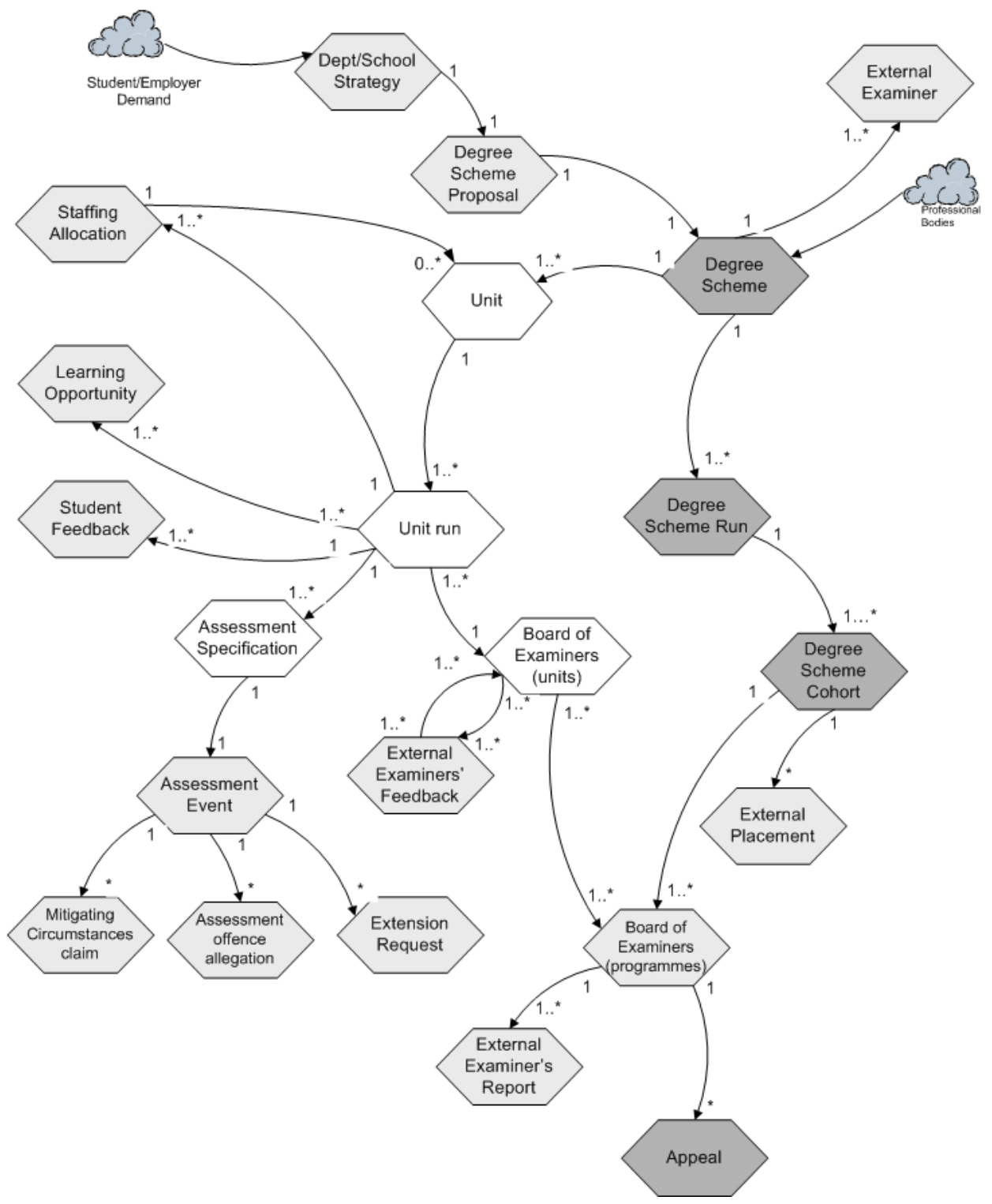

\subsection{Faculty of CEMS in the UWE}

The UOW diagram in Figure 4 illustrates the formal side of programme management in the UWE.

It is separated into two distinct parts: an operational part centred on the module run UOW and a developmental part centred on Programme specification. Programme specifications are seen as generated from work in curriculum design and faculty planning, 
and themselves generate more detailed specification work as well as two kinds of approval event: validation and accreditation events.

Figure 4 UOW diagram (UWE) (see online version for colours)

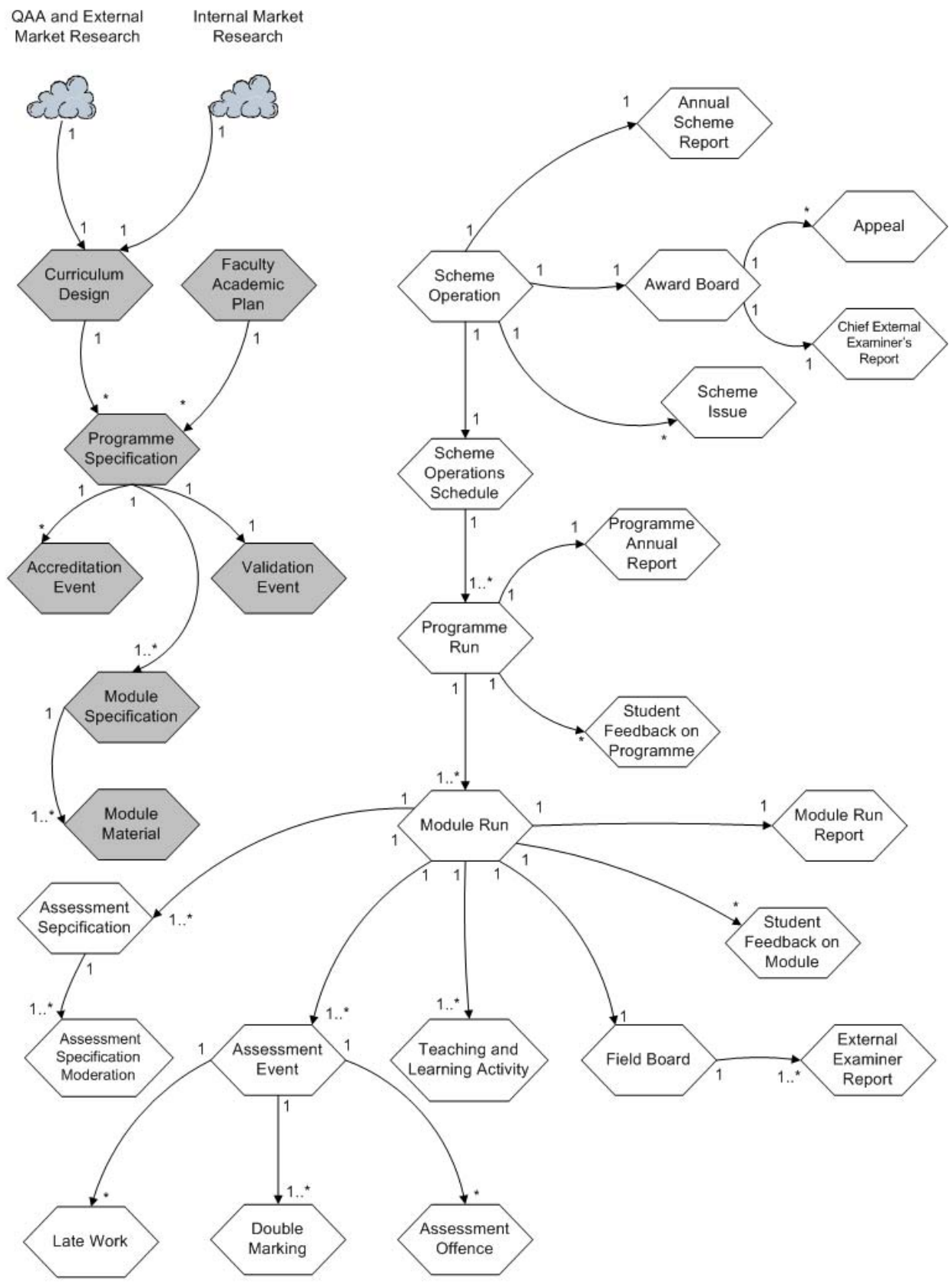


The module run UOW, itself generated by programme run, generates the teaching and learning activity, assessment specification, and assessment event UOWs, and the end of session examination board (for a disciplinary field), as well as two kinds of feedback reporting: Student Feedback on module, and student feedback on programme. Programmes are seen as part of schemes, which operate according to a schedule. The scheme here is a whole set of programmes in a school or faculty running under the modular assessment regulations. Programmes are reported on in an analogous way to modules, and the culmination end of session examination board (award board), which makes progression decisions for students, is conducted at scheme level.

\subsection{Comparing the application of Riva at the UB and the UWE}

Comparing the two UOW diagrams, we had to conclude that, even though we felt that there was a broad similarity in the processes at the two sites, and even though we had shared and overlapping experience of the management and development of taught programmes, which might have been expected to produce similar analyses, the diagrams that we produced were quite dissimilar - in the names and numbers of UOWs, and in the relationships between them.

Some of the differences are terminological, so could be fixed by agreeing a shared vocabulary. Sometimes there were different decisions about whether something was important enough to include (e.g., 'mitigating circumstances'). More generally though, the diagram for the UWE is a little more complex than that for the UB and shows a clearer separation between operational and development activity, as well as a little more emphasis on planning and reporting activity. The UOW diagram for the UB is more integrated around the central concepts of degree scheme and cohort while the UWE diagram represents a more elaborated modular scheme. The situation at the UWE looks more bureaucratic than at the UB, where a greater level of autonomy appears to be enjoyed at departmental level. Development processes at the UWE are more formalised than those at the UB.

Did this dissimilarity mean that higher education, at least as a set of processes, was not the same in the UB and the UWE departments? Does this in turn imply that organisations can be in the same business, but still have different process architectures?

\section{Process architectures from essential UOWs}

At this point, the two researchers based at the UOW considered that, in our first attempts at developing process architectures for our respective institutions, we might have made the mistake of staying too close to operational reality, partly because of our familiarity with and involvement in them, which had led us to produce descriptive, low-level architectures, so obscuring the essential business of higher education by focusing on DBEs as well as EBEs. In effect, we had failed to filter out the DBEs from the EBEs when applying step 2 of the Riva method.

The UWE researchers therefore proceeded to redevelop the process architectures by reconceiving what they took, upon reflection, to be the set of EBEs of programme 
development and delivery in higher education. To do this necessitated taking a step back from operational realities, to reconsider what the EBEs were. They carried out this exercise as a brainstorming exercise and produced a set of five EBEs: teaching and learning activity, assessment event, curriculum element, student, and staff member.

Since they were interested in the lifetime of these EBEs in both CEMS in the UWE and the School of Management in the UB, it was agreed that these EBEs were also UOWs. Starting from these five UOWs, their next step was to develop a UOW diagram. The resulting UOW diagram, including generates relationships between the UOWs, is shown in Figure 5.

Figure 5 UOW diagram (see online version for colours)

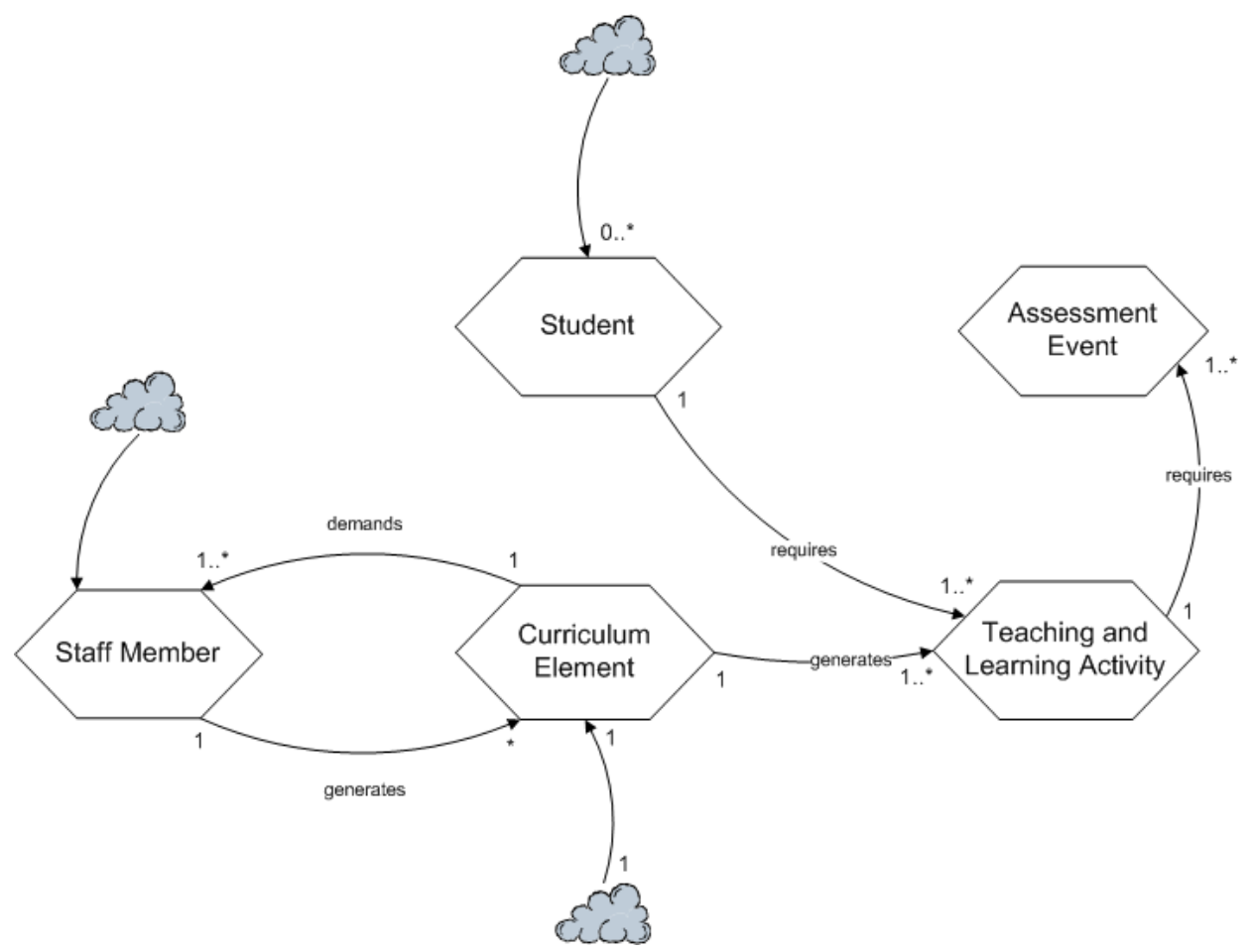

Staff Member UOWs generate Curriculum Element UOWs in the sense of proposing ideas for what should be taught. Conversely, the content of teaching (derived from the curriculum element UOWs) demands the existence of staff to cover them. These curriculum element UOWs also generate teaching and learning activity UOWs: teaching activities for the staff and learning activities for the students. To know how effective learning activities have been requires assessment events, which are shown in the figure as being required by the Teaching And Learning Activity UOW.

Subsequently this UOW diagram was discussed with, and validated by, the third researcher, based in the UB

Following step 8 of the Riva method (see Section 2.2), the distinctive DBEs at the two sites were now independently integrated into the UOW diagram. 


\section{Process architectures including DUOWs}

It was not difficult to produce a consensus about the EBEs that would need to be present in any higher education institution, whatever the social, cultural or managerial context. But, to produce a process architecture reusable in a variety of universities in the particular context of England and its particular regulatory framework, it was necessary to add to the EBEs (and associated UOWs) a set of DBEs (and associated DUOWs).

The DUOWs are important to an organisation, but they do not represent the UOWs, which relate to the type of business it is in, but rather represent the decisions which have been taken about the way in which its work is to be carried out. In the case of universities, with their integration into a nationwide set of arrangements for the maintenance of quality and standards, these decisions are still common across a large number of institutions, even if the way they are made is different in specific locations.

We wanted to model the organisations at both the UWE and the UB through the construction of a UOW diagram which would include DBEs and EBEs in ways which reflected each organisation's own method of managing teaching programmes. But, unfortunately, Ould's work does not provide a detailed treatment of how UOWs based upon DBEs should be integrated into a UOW model based upon just UOWs derived from EBEs. So the researchers needed to do two things: to modify Ould's nomenclature so that concepts such as UOWs based upon DBEs might be referred to easily, and to evolve a method for achieving the integration.

For the nomenclature modification, it was decided that UOWs derived from DBEs should be named derived units of work (DUOW, and UOWs derived from EBEs should be renamed essential units of work (EUOW).

\subsection{Faculty of CEMS in the UWE}

The integration method was developed by the two researchers at the UWE as follows. First they assumed that many of the EUOWs in the initial UWE EUOW diagram (see Figure 4) were candidate DUOWs, and they tried to cluster these according to the reconceived EUOW diagram presented in Figure 5. The results are recorded in Table 3.

They next considered what the relationship was between each cluster of old EUOWs and the associated new EUOW. In theory, it was possible that in some cases the old EUOWs could be conceived as being generated from a new EUOW; in other cases as being specialisations of a new EUOW.

They decided to replace the teaching and learning activity EUOW with old EUOWs like module run, programme run, module material, and so on because a teaching and learning activity did not generate these things, rather these were designed instances of teaching and learning activities. But, before replacing them as DUOWs, it was decided to find new names for some of them that better described their denotations: so, for example, module run was renamed to module delivery, and student feedback on module to staff and student feedback. In addition, they also thought that some new DUOWs were needed such as change to programme specification, new resource, and Room; and these have been integrated into the new EUOWs and DUOWs diagram, as Figure 6 shows. 
Table 3 Clustering candidate DUOWs around the reconceived EUOWs

\begin{tabular}{|c|c|}
\hline Clustering DUOWs around reconceived EUOWs & Old EUOWs from Figure 4 \\
\hline \multirow[t]{2}{*}{ Match new EUOWs (see Figure 5) } & Teaching and learning activity \\
\hline & Assessment event \\
\hline \multirow[t]{5}{*}{ Related to curriculum element new EUOW } & Module specification \\
\hline & Curriculum design \\
\hline & Programme specification \\
\hline & Accreditation event \\
\hline & Validation event \\
\hline \multirow[t]{9}{*}{ Related to assessment event new EUOW } & Assessment specification \\
\hline & Late work \\
\hline & Double marking \\
\hline & Assessment offence \\
\hline & Chief external examiner's report \\
\hline & Award board \\
\hline & Appeal \\
\hline & Field board \\
\hline & External examiner report \\
\hline \multirow[t]{12}{*}{ Related to teaching and learning activity new EUOW } & Faculty academic plan \\
\hline & Scheme operation \\
\hline & Annual scheme report \\
\hline & Scheme issue \\
\hline & Scheme operations schedule \\
\hline & Programme run \\
\hline & Programme annual report \\
\hline & Module run \\
\hline & Module run report \\
\hline & Student feedback on module \\
\hline & Student feedback on programme \\
\hline & Module material \\
\hline
\end{tabular}

They considered whether the assessment event EUOW should be treated in the same way, but decided that, because the assessment event EUOW was distinct from all of the associated old EUOWs, like assessment specification, it should be retained in the new EUOW and DUOW diagram. Each original EUOW was then considered in turn to judge whether it was a mandatory or optional DUOW associated with an implicit DBE. For example, assessment specification was deemed to be a mandatory DUOW, while assessment offence and late work were both deemed to be optional DUOWs. Before adding them as DUOWs, some of them were renamed: for example, late work was renamed to late work submission, award board to award board event, and so on. In addition, two new, formerly overlooked, DUOWs were introduced: marking event and extenuating circumstances. The result can be seen in Figure 6. 
Figure 6 EUOW and DUOW diagram (UWE)

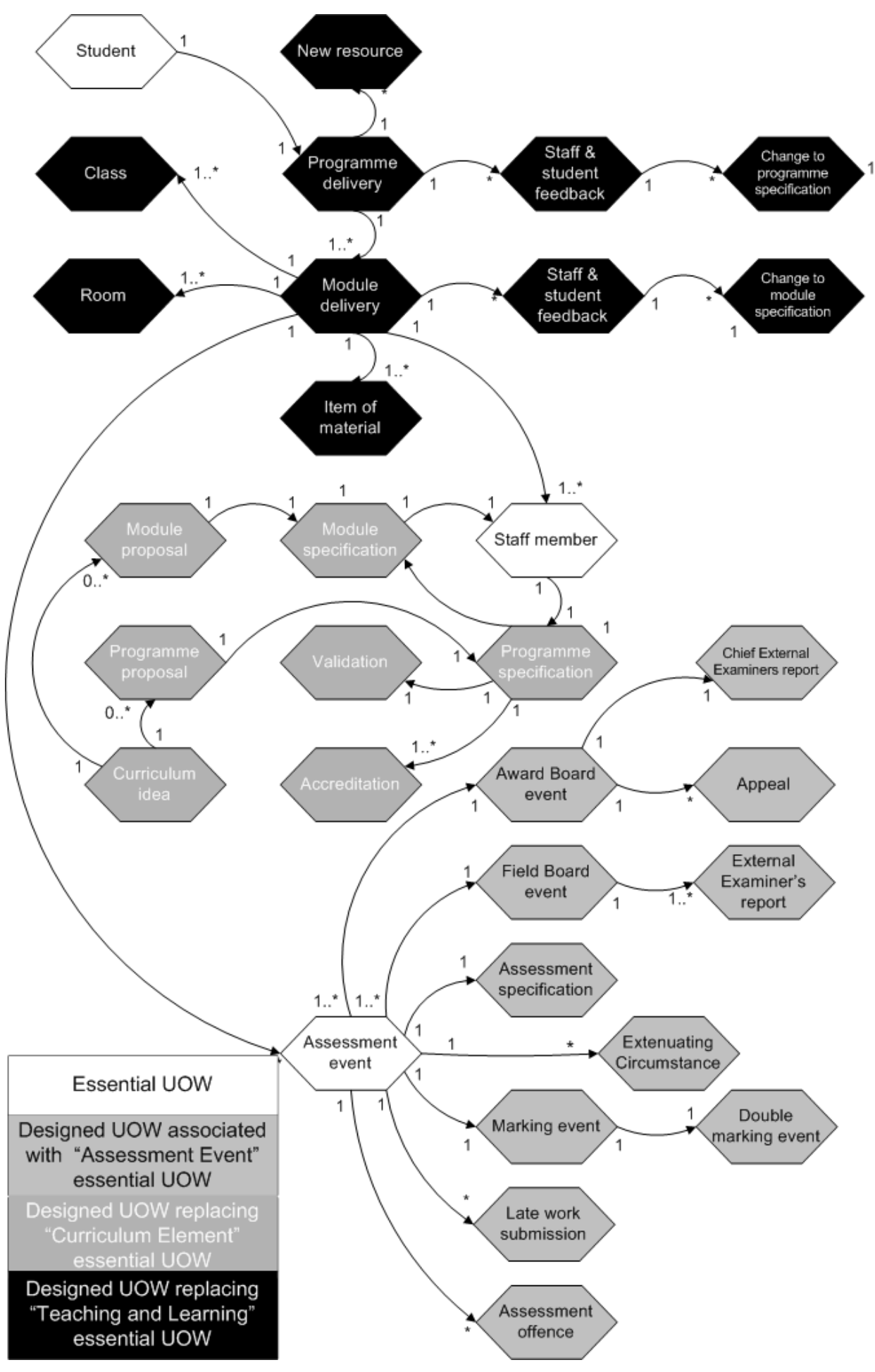


As with the teaching and learning activity EUOW, the curriculum element EUOW was replaced by old EUOWs, some appropriately renamed, as well as by some new DUOWs, such as curriculum idea.

After completing the new UOW model, they had some residual concerns. First, they were not sure which EUOWs or DUOWs were associated with the yearly cycle of judging both student progress and the five yearly adjustments of curriculum and programmes. Second, they were not convinced that there was a 'generates' link between the curriculum element EUOW and the teaching and learning activity EUOW (see Figure 5). On reflection, however, they considered that the award board EUOW was the locus for student progression decisions. The other two concerns remained.

Figure 6 shows the EUOWs and DUOWs diagram that resulted from the application of the method just described.

Figure 7 EUOW and DUOW diagram (Bath) (see online version for colours)

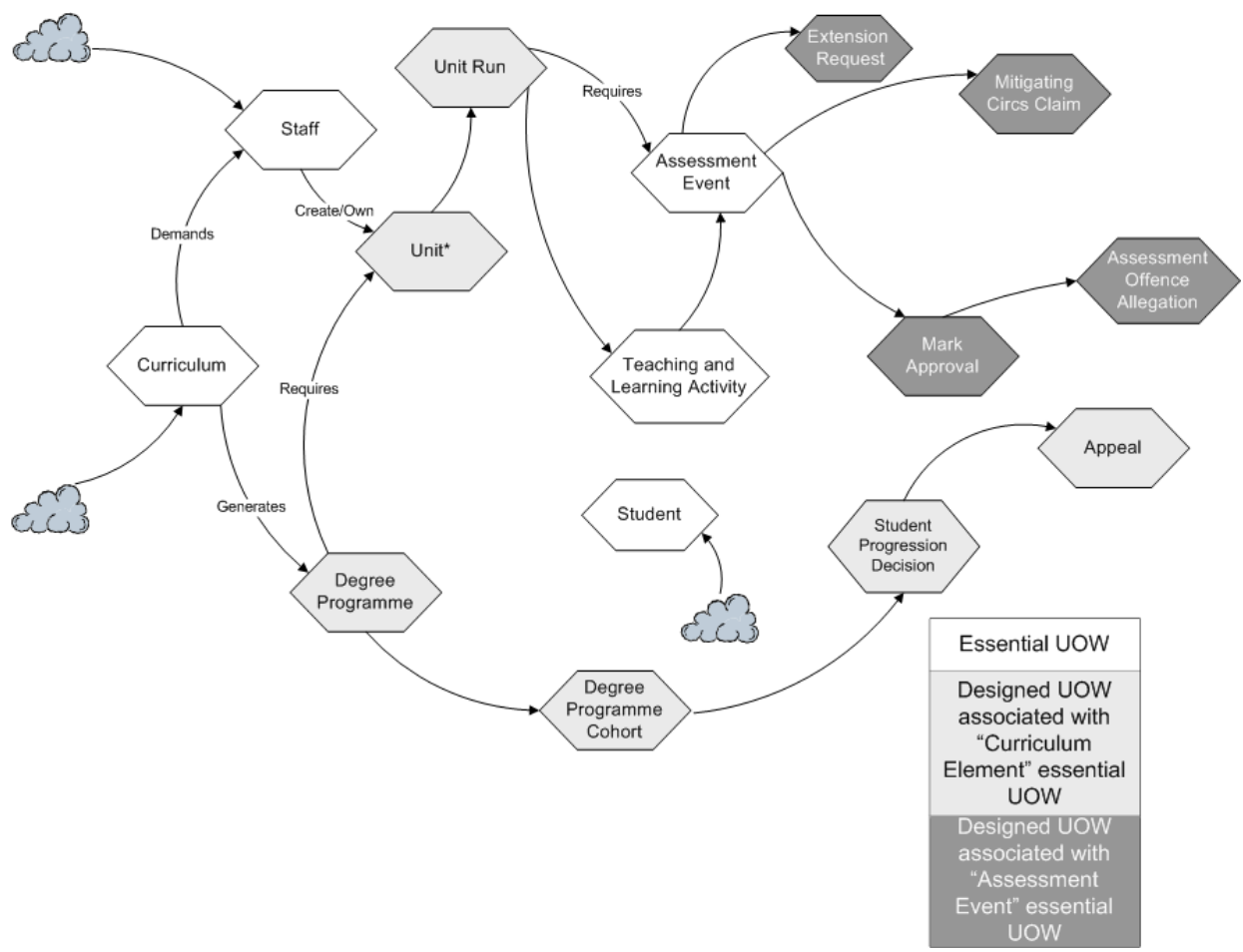

\subsection{School of Management in the UB}

The key relationships which needed to be illustrated when integrating the UB's DUOWs into the EUOW diagram were those between unit, assessment event and mark approval on the one hand, and between degree programme, degree programme cohorts and student progression decision on the other. Figure 7 shows the resulting EUOW and DUOW diagram for the UB that combines both EUOWs and DUOWs. In the figure, white EUOWs represent EUOWs derived from EBEs; dark grey DUOWs represent DUOWs filtered from EBEs and associated with the assessment event EUOW; and light grey 
DUOWs represent UOWs filtered from EBEs associated with the curriculum element EUOW.

Mark approval is a DUOW that covers the receipt of a piece of assessed work, through its marking, moderation and the formal acceptance of the mark. The assessment offence allegation DUOW (e.g., suspicions of plagiarism) can be generated within marking, hence by the Mark Approval DUOW.

The student progression decision DUOW covers all the exam board activity concerning discussion of whether or not students have met the requirements of the particular stage of their programmes. It includes, for undergraduate programmes, degree classification decisions. Marks are not changed in any way within this process. But appeal DUOWs can be generated. Students are allowed to appeal against decisions on progression to the next year and on the award of qualifications, but not against individual marks.

\subsection{Comparison of the two EUOWs and DUOWs diagrams}

The similarities between the EUOW and DUOW diagrams at the UWE and the UB are as follows:

1 Either the full set of EUOWs (see Figure 5), or some of the full set plus sets of DUOWs that replace the remaining EUOWs, exist on the UB and the UWE diagrams respectively.

2 Some of the expected dynamic relationships (see Figure 5) exist on both diagrams. For example, the teaching and learning activity requires assessment event and curriculum element demands staff member relationships exist on both diagrams.

3 The assessment event EUOW generates similar DUOWs at both the UB and the UWE: assessment offence and assessment offence allegation; appeal and appeal; and extenuating circumstances and mitigating circumstances.

But the diagrams also contain some important differences:

1 At the UWE, the Curriculum Element is not dynamically linked to the DUOW

Teaching and Learning Activity while at the UB it is indirectly linked.

2 At the UB, Student is not dynamically linked to Teaching and learning Activity.

Taken together, these observations seem to indicate that the revised EUOW diagram (see Figure 5) does provide a reasonable 'essential' process architecture for both the UWE and the UB contexts, with perhaps the links both between teaching and learning activity and curriculum element, and between student and teaching and learning activity needing to be reviewed. (By 'essential' here, we mean a process architecture derived from an EUOW diagram).

In addition all of the DUOWs for both contexts were relatively easy to integrate into their respective EUOW models.

While on the one hand, these results do seem to provide support for Ould's assertion about the invariant nature of the process architecture for organisations in the same business; on the other hand, it is clear that the most representative and useful process architecture for a higher education organisation is one derived from a EUOWs and DUOWs diagram. 


\section{General discussion}

\subsection{EBEs and DBEs - learning from comparative process architecture analysis}

The focus of this paper is the testing of Ould's proposition that, for any type of organisation, an essential process architecture can be identified which will not vary with culture, managerial methods or inherited forms of structure. There should be a set of EBEs which, when the 'generates' relationships between them are worked out, will form an EUOW diagram which can be taken as the basis for the essential process architecture. The DUOWs are then added by each organisation to suit its preferred approach to these processes.

In this study, we developed a set of EBEs which, at a general level, seem to be transferable across different university departments. All university departments will have a curriculum (otherwise there would be no way of giving it any kind of disciplinary identity), teaching events (whether formal or informal, real or virtual), assessment events (because without this no accreditation of a student's achievement is possible) and students.

We have developed an EUOWs model derived solely from EBEs (see Figure 5), which we argue could be applied not only to the institutions examined here, a university with a modular programme and a university whose focus is on linear degree programmes, but also to other types of taught provision in higher education. For example, the EBEs have been created at a sufficient level of abstraction to cover work-based or distance learning, since there is no mention of classroom activity. They could cover programmes where the assessment is based entirely on projects or on examinations, because there is no specification of the form of assessment which is to take place. And the EBEs will cover programmes where certification or the award of credit takes place at different points in the academic cycle whether after each module is taken or only when a student has completed the entire programme.

As explained below, however, this means that the EBEs can be quite abstract. A curriculum element, in particular, is sometimes a very formal entity, but not in every institution. It must exist, so that the university can decide what courses to run and what staff to employ, but it is not always going to have a formal existence as a single, defined object of management. In order to accommodate this when DBEs are added to the diagram, we have assumed that curriculum element will continue to exist in some form, despite the fact that in one institution (the UB) almost all development activity takes place around degree programmes. This point is discussed below.

\subsubsection{Are the same EBE's the foundation of process architecture in both institutions?}

In general, not all of the same EBEs are the foundation of process architecture in both institutions. In Riva an EBE is an entity with a definable life history whose instances can be managed in a regular, formal way. With some of our entities, this is the case in one institution but not in the other. The EBE 'curriculum element' is the most difficult in this respect. As a department working with a strongly modular university framework, the CEMS faculty at the UWE had a set process for handling changes to its provision within a faculty curriculum. New modules were proposed and old ones withdrawn within a process of curriculum management. New degree programmes (or 'awards') were 
developed on the basis of existing modular provision, as part of an overlapping suite of degree courses. Named individuals were responsible for overseeing parts of the curriculum (subject areas or 'fields') and for the curriculum as a whole.

In the School of Management in the UB, on the other hand, 'curriculum element' had no formal life history of its own. It simply emerged from the processes of developing and managing the degree programmes. Some modules were shared between degree programmes, but the tradition within the School was for courses to be developed by the specialist members of staff rather than being directed by the senior managers. The curriculum was mostly emergent: it was expected that there would be units offered in certain broad subject areas within business and management, but exactly what they were, and how they were assessed, could be subject to the interests and priorities of the members of staff involved. The managers of degree programmes could influence and discuss units with members of staff, and were consulted about any proposed changes, but did not exercise the kind of strategic role in teaching provision that was formalised at UWE in the 'Field'.

\subsubsection{Are the relationships between EBEs and DBEs the same in both institutions?}

In general, the relationships between EBEs and DBEs are not always the same in both institutions. In Riva the relationship between one UOW and another is invariably of the 'generates' variety: that is, one UOW creates instances of another UOW in the course of its life history. Where 'curriculum element' was a formally managed business entity, as at the UWE, it is clear that the modules were generated by it. Subjects were put on and off the curriculum as the needs of the discipline developed and, as long as they were offered, someone was found to teach them.

Where 'curriculum element' was not a formal entity, as at the UB, modules were not invariably developed in such a consistent way. Some modules existed because of the needs of a particular degree programme: so the creation of a new degree would lead to new modules. Others were created because of the research interests of a particular member of staff and were treated as, in effect, the member of staff's property: when the staff member was on study leave, the module could be removed from the offerings to degree programmes. The module ceased to be offered at all when the member of staff left. (Of course, this could only apply to modules which were not compulsory on any degree programmes.) So, as noted above in Section 4.1, the answer to the question 'what generates a module?' is that it was sometimes degree programmes and sometimes the members of staff themselves.

\subsubsection{Are the same DBEs apparent in the process architectures of the two institutions?}

In general, not all of the identified DBEs are common to both institutions: for example, the Extension Request DBE at the UB does not have a counterpart at the UWE. The strongest similarities between the DBEs in the two sets of process models come in some of the more detailed aspects of the work of academic departments. Both institutions had processes for addressing 'assessment offence allegations', 'appeals' and 'mitigating circumstances claims'. These entities appear in similar places on the UOW diagrams, being generated by 'assessment event' or 'progression decision'. 
These are the types of entity whose life is most easily encapsulated in a short, documented procedure. In the two institutions examined here, these documents were produced by the central quality departments of the universities rather than being left to individual departments. With an increasing level of oversight from external bodies such as the Quality Assurance Agency, the Funding Council and the Independent Adjudicator, it is likely that universities feel bound to institute regular processes to cover the welldefined activities. A similar comparability across organisations may exist in industries with as much or more official regulation: health, telecommunications, energy and others.

Ould presents the EBE's as the entities that are likely to be present in all organisations performing similar tasks, with the DBEs reflecting the local variations. However, largely as a result of this regulatory context, we have found it easier to identify some of the DBEs in the School of Management in the UB with similar DBEs in the faculty of CEMS in the UWE.

\subsection{Observations on Riva}

From our experiences of working with Riva, we are able to make a number of observations about it.

First, Ould has observed that "a Riva process architecture is an invariant for an organisation that stays in the same business", and again, that "for an organisation in a given business there is a given process architecture". It is instructive to ask what is the meaning and significance of these statements and others like them. The key terms to understand seem to be 'Riva process architecture' and 'given business' or 'same business'. So what do these terms mean? It turns out that a Riva essential process architecture, at least its 1st-cut version, may be derived in a relatively straight forward manner from an associated EUOWs diagram. The latter shows the EUOWs, which means the EBEs that the organisation is interested in, and their particular dynamic interrelationships, including their cardinalities, for example one-to-one (1 to 1) or one to one or more (1 to $\left.1 .{ }^{*}\right)$. Looking next at the idea of a given business, unfortunately there is no obvious precise scheme in the literature for classifying businesses unambiguously into distinct types. In other words, there is no obvious classification scheme for categorising business such that an impartial observer might apply an objective test to one in order to ascertain its exact type. At least, there is no obvious scheme other than determining that business's EBEs, and thus the EUOWs characterising the business, and their interrelationships, including cardinalities. But this reduces the original assertion to something like 'a Riva process architecture' (i.e., a set of EUOWs and their dynamic interrelationships) "is an invariant for an organisation that stays in the same business" (i.e., that retains just theses EUOWs dynamically related in just these ways). In other words "a Riva process architecture is an invariant for an organisation that maintains exactly that Riva process architecture". Although this is a true statement it is tautological.

Second, Riva, as documented, focuses primarily upon EBEs: it pays much less attention to DBEs. However, in our work, it seems that the EBEs, EUOW models and corresponding essential process architectures for higher education are relatively simple, highly generic artefacts; and it is not clear how useful they would be as a starting point for identifying a higher education institution's processes such that the resulting processes, working together, could constitute a functioning organisation. It is only when the DBEs are taken into account that an EUOW and DUOW model and its associated 1st- and 2nd-cut process architectures seem to offer the potential for effective use in an 
organisation and, in highly regulated sectors like higher education, potential for effective reuse across organisations.

\section{Conclusions}

\subsection{Results}

The results of this investigation provide some support for the existence of an essential process architecture for supporting teaching in higher education departments. Here the term essential process architecture refers to a process architecture based upon just EBEs. Thus, some support is also provided for Ould's (2005) assertion that organisations in the same business will have the same process architecture. Such support, though limited, justifies allowing this essential process architecture to be reused for developing or appraising both modular and linear universities, work-based learning courses, distance learning courses, entirely project-based assessment programmes, and entirely exam-based assessment programmes.

In addition the work has emphasised the importance of the role of DBEs for particularising essential process architectures in particular contexts. And during the work, a first method was evolved for integrating DBEs into an organisation's essential process architecture.

\subsection{Potential problems and limitations}

Two problems in particular arose during the course of the investigation. First: the result of the second attempt to discover the essential process architecture for higher education (see Figure 5) seemed to apply, not just to higher education, but also to education in general. However, on reflection, this was deemed not to be a problem as we were trying to find an essential process architecture for education, not one that differentiated higher education from other levels of education.

The second problem is implicit in the question "How do we know when two organisations are in the same business?" Until an EBE-independent method for accurately classifying businesses is found, common sense judgements must be relied upon. But, if a more precise method is not found, then the question arises over whether or not the invariant assertion is testable in any useful sense. However, because of the potential both for reusing process architectures, and using them for appraisal, it seems worth continuing to try to find a method for classifying businesses more objectively and more precisely.

\subsection{Future work}

Future work that needs to be undertaken includes the following:

- searching for an EBE-independent method for classifying businesses objectively and accurately

- repeating the comparison study with other kinds of organisation

- refining the method for integrating DBEs into an EBE-based UOW diagram

- making more precise the Riva concepts of the EBE, DBE, UOW and 'generates'. 


\section{References}

Ackroyd, S. (2002) The Organization of Business, Oxford University Press, Oxford.

eTom, Business Process Framework (eTom) [online] http://tmforum.org/browse.aspx?catID=1647 (accessed on 19th December 2012).

Finkelstein, A. and Shattock, M. (2001) CAPSA and Its Implementation: Report to the Audit Committee and the Board of Scrutiny, University of Cambridge, Cambridge University Reporter No 5861 [online] http://www.admin.cam.ac.uk/reporter/2001-02/weekly/5861/ (accessed 8th May 2012).

Fowler, A. and Gilfillan, M. (2003) 'A framework for stakeholder integration in higher education information systems projects', Technology Analysis and Strategic Management, Vol. 15, No. 4, pp.468-489.

Frankel, D.S. (2003) Model Driven Architecture: Applying MDA to Enterprise Computing, Wiley, New York.

Green, S. and Ould, M. (2005) 'A framework for classifying and evaluating process architecture methods', Software Process Improvement and Practice, Vol. 10, No. 4, pp.415-425.

Grover, V., Kettinger, W. and Teng, J. (2000) 'Business process change in the 21st century', Business and Economic Review, January-March, Vol. 46, No. 2, pp.14-18.

Hammer, M. (1996) Beyond Reengineering, Harper Collins, New York.

Harmon, P. (2003) Business Process Change, Morgan Kaufmann, San Francisco.

Kavakli, V. and Loucopoulos, P. (1999) 'Goal-driven business process analysis application in electricity deregulation', Information Systems, Vol. 24, No. 3, pp.187-207.

Kawalek, P. and Snowdon, R.A. (2003) 'Active meta-process models: a conceptual exposition', Information and Software Technology, Vol. 45, No. 15, pp.1021-1029.

Kettinger, W.J., Teng, J.T.C. and Gupta, S. (1997) 'Business process change: a study of methodologies, techniques, and tools', MIS Quarterly, Vol. 21, No. 1, pp.55-80.

Lankhorst, M. et al. (2005) Enterprise Architecture at Work: Modelling, Communication and Analysis, Springer, Berlin.

Lunn, K., Lindsay, A. and Vaarama, M. (2003) 'Traceability in requirements through process modelling, applied to social care applications', Information and Software Technology, Vol. 45, No. 15, pp.1045-1052.

Malone, T., Crowston, K. and Herman, G.A. (2003) Organizing Business Knowledge, MIT Press, Cambridge MA.

Mintzberg, H. (1979) The Structuring of Organizations, Prentice-Hall, New Jersey.

Ould, M. (2005) Business Process Management: a Rigorous Approach, British Computer Society, Swindon.

The Open Group (2002) The Open Group Architecture Framework (TOGAF), Version 8, 'Enterprise Edition', The Open group, Reading, UK.

Weaver, P., Lambrou, N. and Walker, M. (2002) Practical Business Systems Development Using SSADM, 3rd ed., Prentice Hall, Harlow, England.

Yin, R.K. (2009) Case Study Research, 4th ed., Sage, London.

Zachman, J.A. (1987) 'A framework for information systems architecture', IBM Systems Journal, Vol. 26, No. 3, pp.276-292. 


\section{Appendix}

For the meaning of the letters ' $\mathrm{A}$ ', ' $\mathrm{C}$ ' and ' $\mathrm{E}$ ' that feature in the process architectures in Appendices 1 to 7, [see Ould, (2005), pp.154-159].

\section{Appendix 1}

Figure A1 The UB school of management 1st cut process architecture

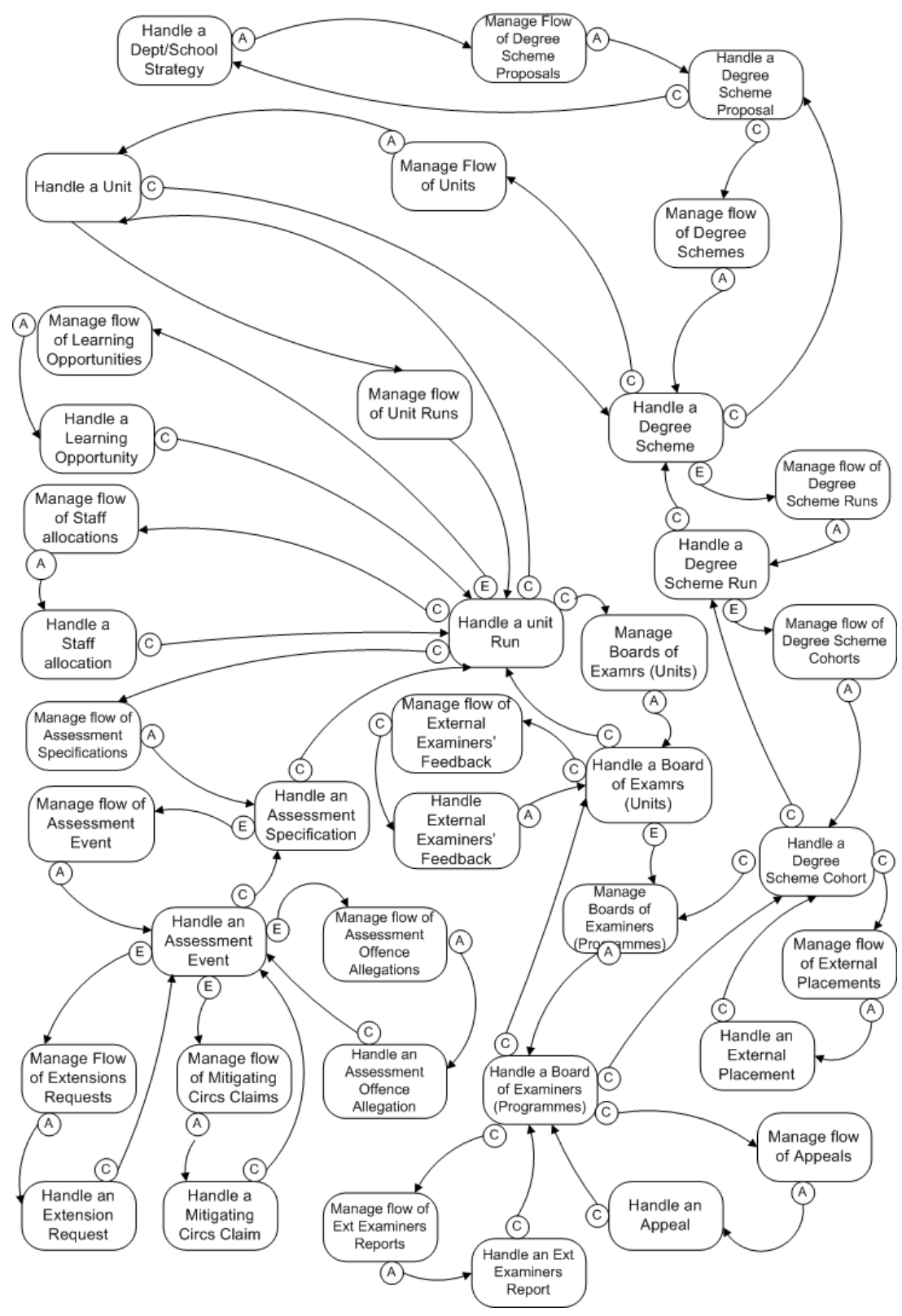




\section{Appendix 2}

Figure A2 The UWE, CEMS 1st cut process architecture (part one) (see online version for colours)

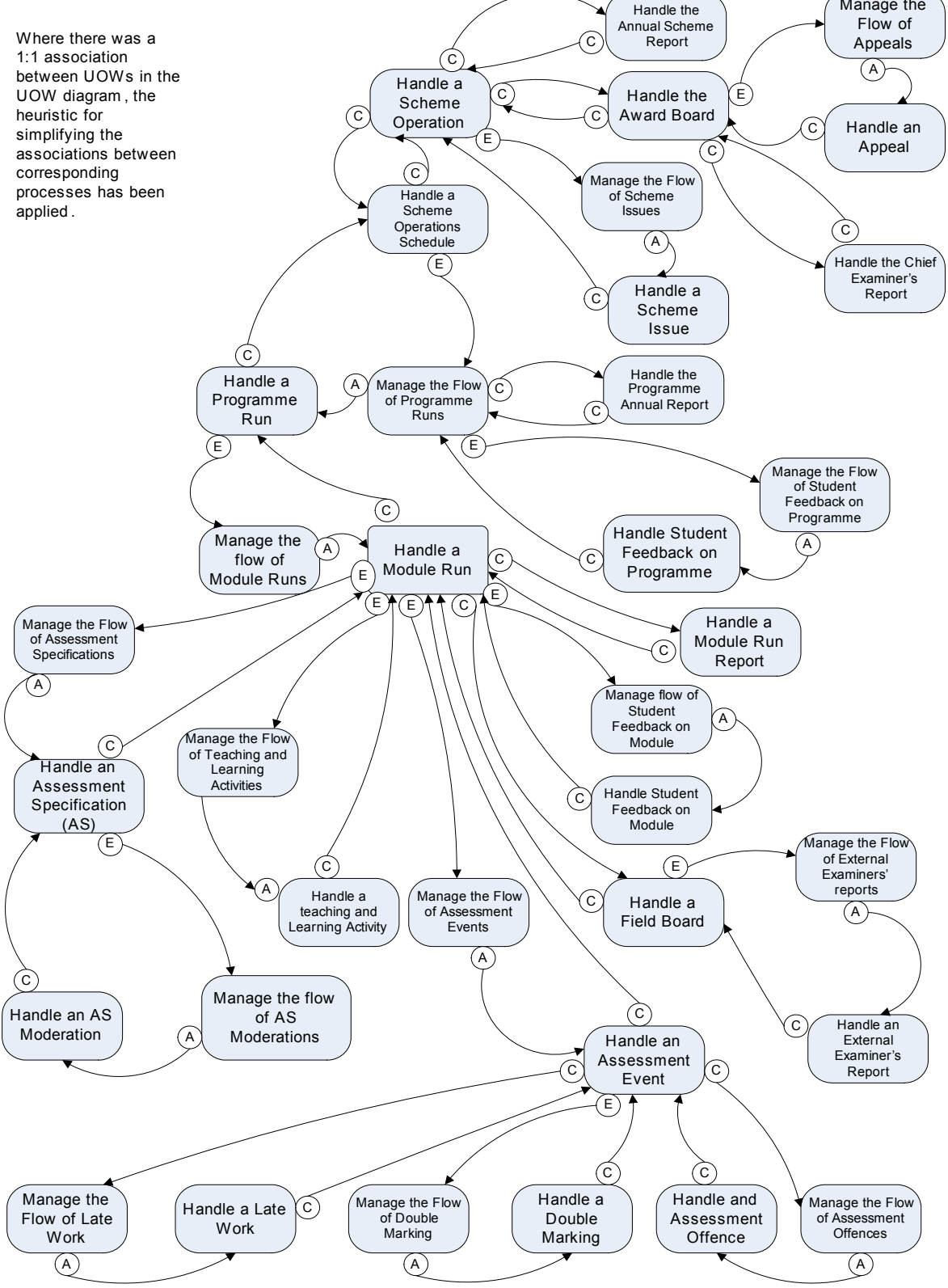




\section{Appendix 3}

Figure A3 The UWE CEMS 1st cut process architecture (part two) (see online version for colours)

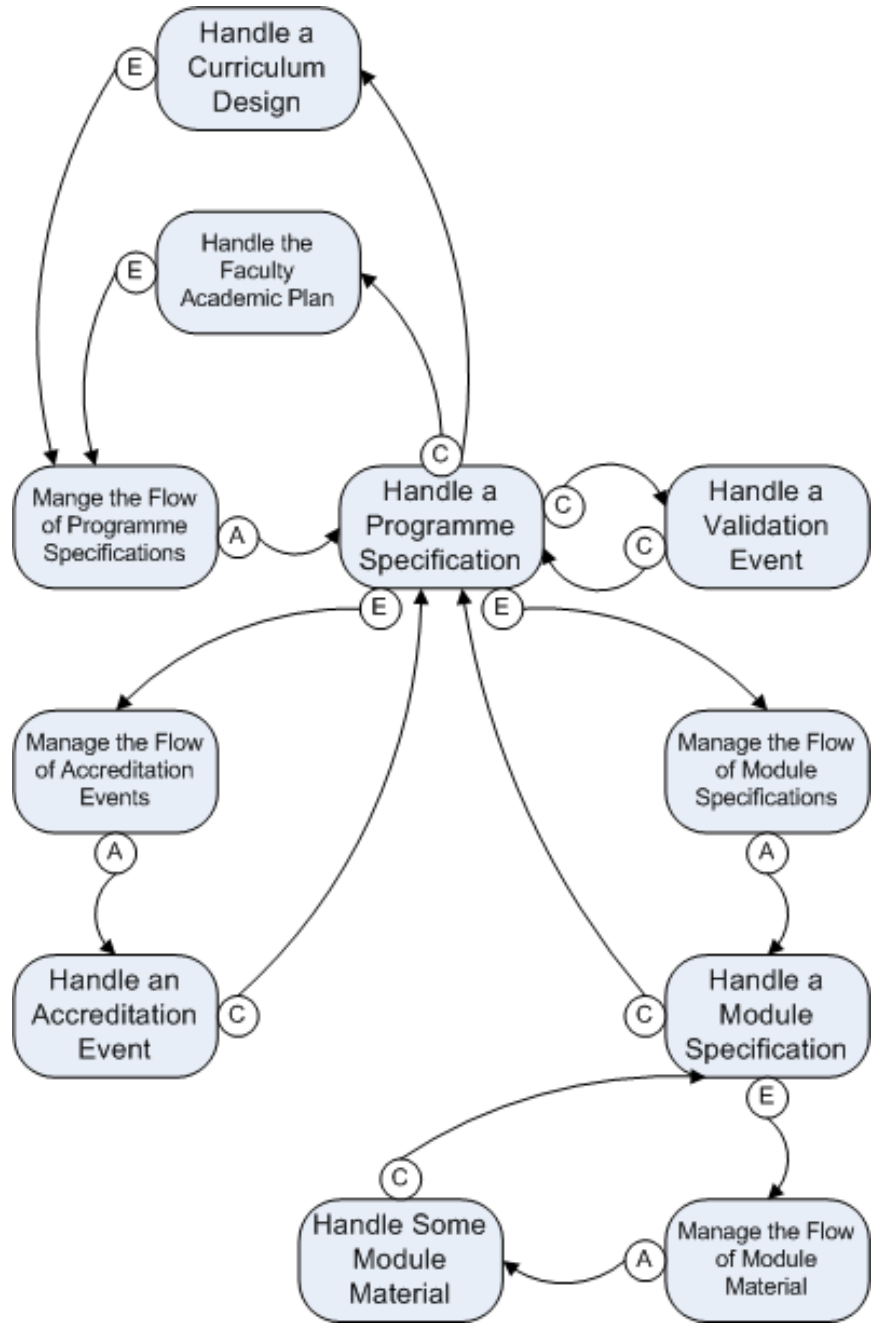

\section{Appendix 4}

1 st cut process architecture derived from the revised UOW diagram

The first-cut process architecture diagram shown below was automatically derived from the UOW diagram shown in Figure 5. 
Figure A4 1st cut process architecture derived from the revised UOW diagram (see online version for colours)

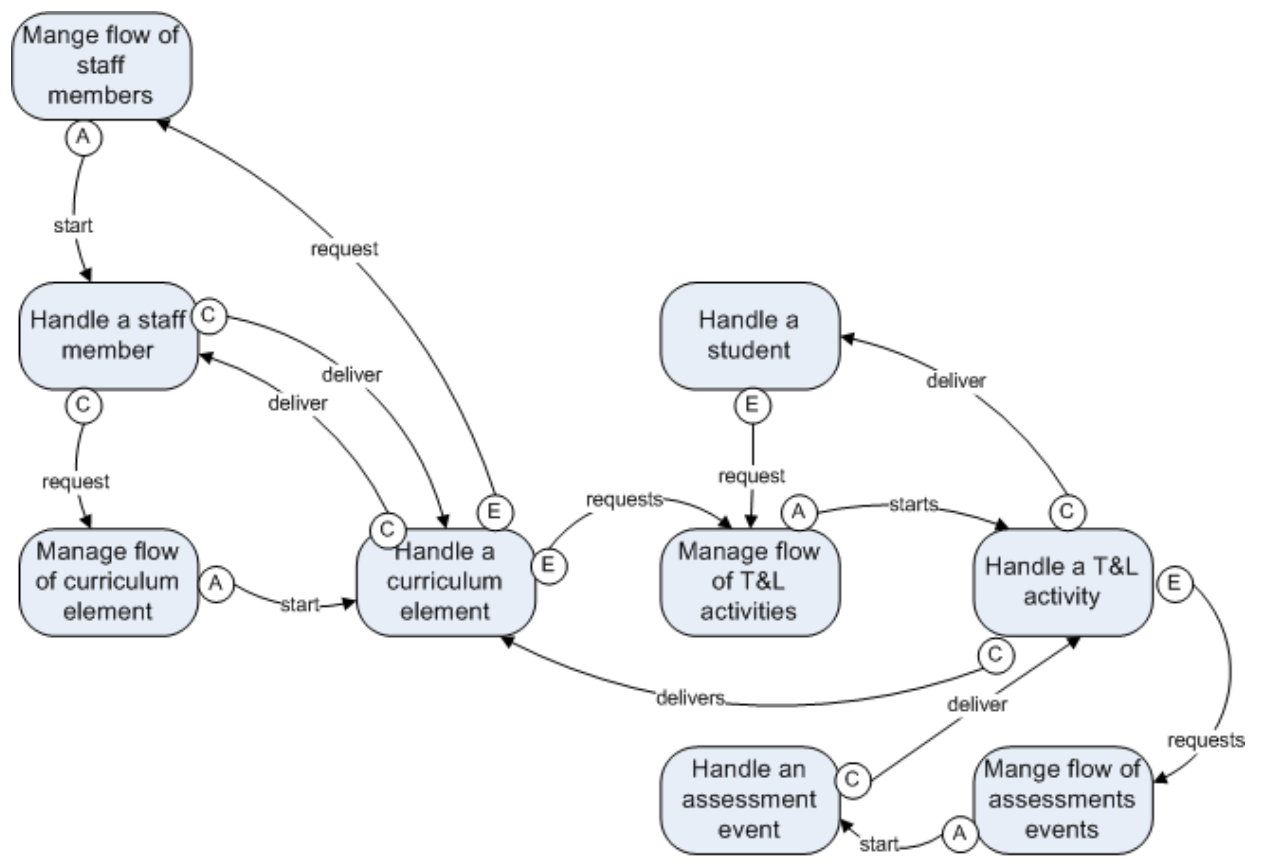

\section{Appendix 5}

2nd cut process architecture derived from the revised UOW diagram

A second-cut process architecture was derived from the first-cut process architecture through the application of heuristics [Ould, (2005), pp.187-192].

Figure A5 2nd cut process architecture derived from the revised UOW (see online version for colours)

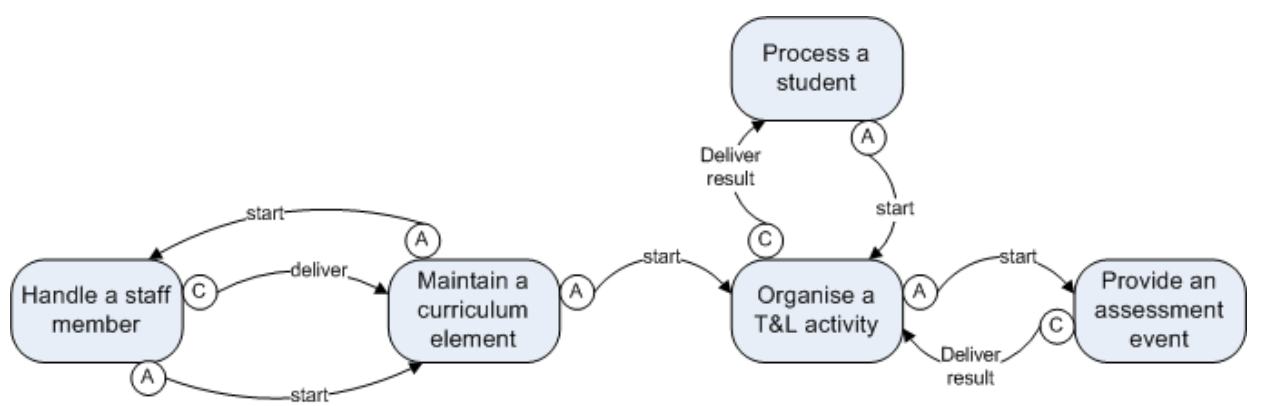




\section{Appendix 6}

1st cut process architecture (the UB) derived from the EUOW and DUOW diagram (the UB)

Figure A6 1st cut process architecture (the UB) derived from the EUOW and DUOW diagram (the UB) (see online version for colours)

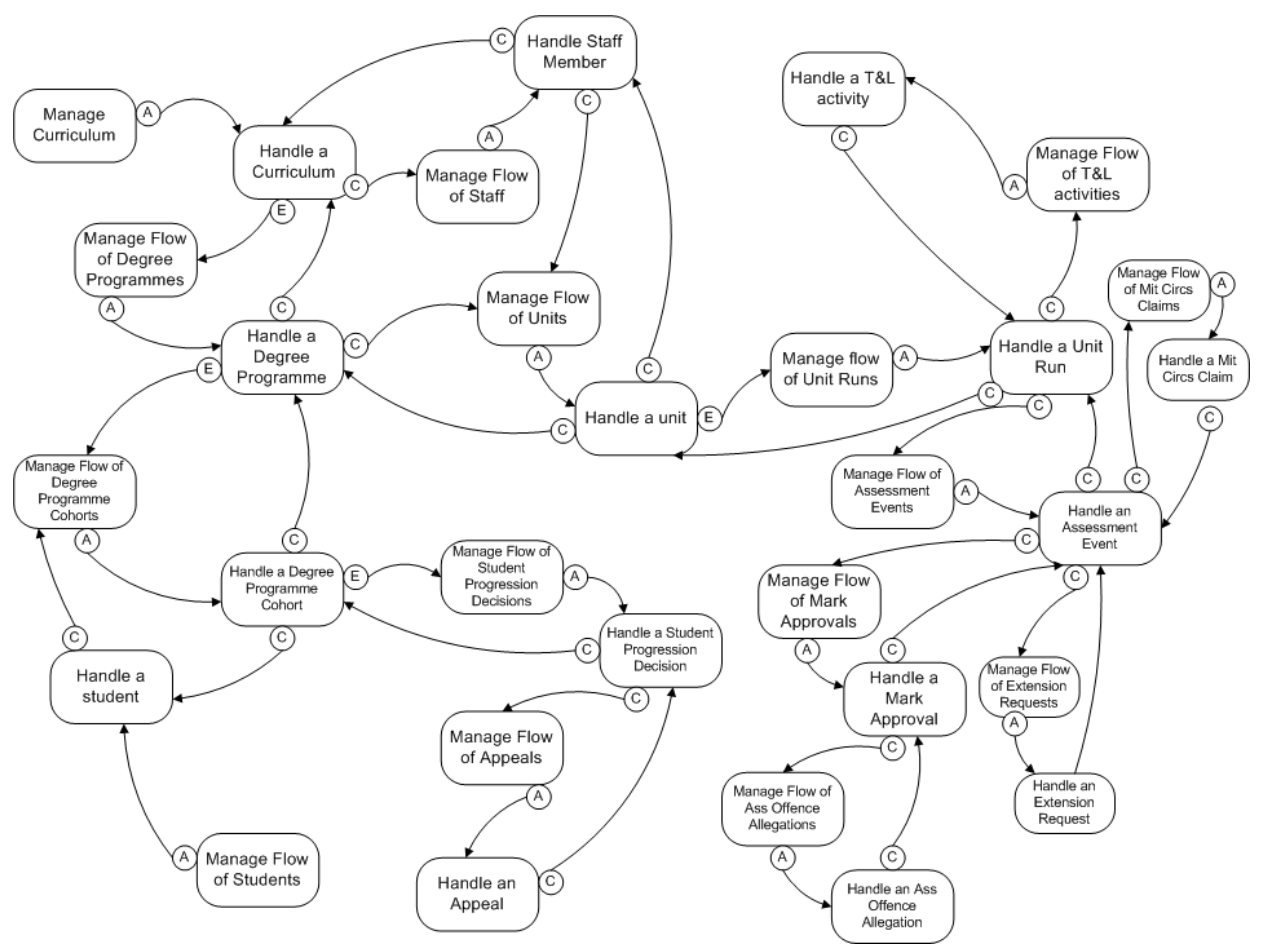




\section{Appendix 7}

2nd cut process architecture (the UB) derived from the 1st cut process architecture (the UB)

Figure A7 2nd cut process architecture (the UB) derived from the 1st cut process architecture (the UB) (see online version for colours)

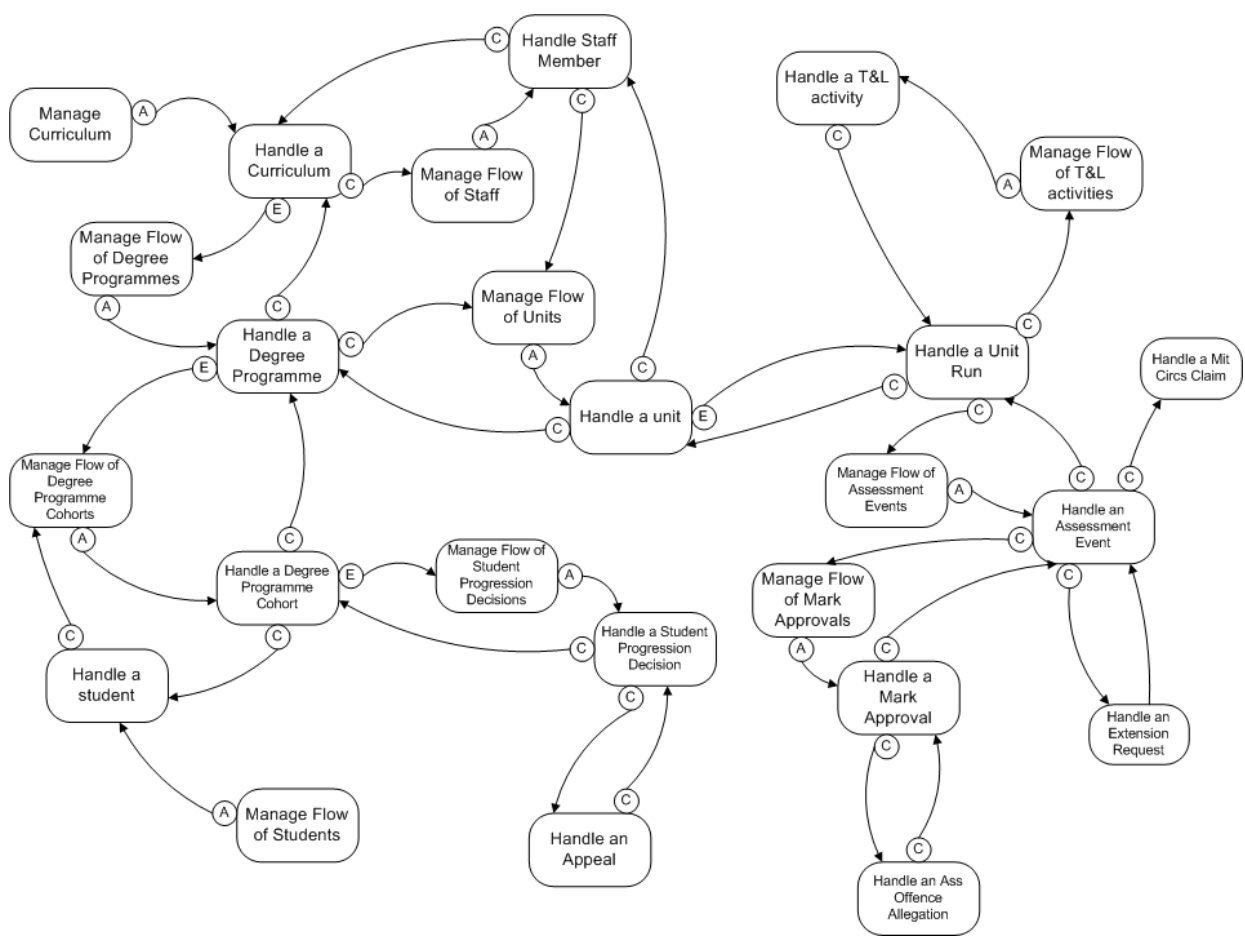

\section{Appendix 8}

Comparing the similarities and differences between the two institutions

\section{The institutions within UK higher education}

Degree-level higher education in the UK is principally delivered through self-governing institutions: not state-owned, but recipients of large amounts of state funding. There are differences in the arrangements for the funding of teaching in the nations of the UK, but all of them have degree programmes managed by universities which are officially funded in the same way at every institution. The two institutions examined here were, and are still, active in teaching undergraduate and postgraduate degree programmes and in research. There is a difference in the proportion of each department's income that comes from teaching and research, but not in the nature of the activities.

The number of course offerings and the amount of teaching work undertaken was also similar. Both organisations undertook a range of teaching from undergraduate, through 
professional development to advanced Masters and research degree level. Both taught students registered within the department and also from other departments in their respective institutions. The School of Management ran 204 modules, with 1,996 student registrations on School programmes: roughly 1,662 FTE (full time equivalent) students. The faculty of CEMS ran 332 modules, with 2,245 student registrations on faculty programmes: 1,924 FTE.

In terms of staff numbers, the two organisations were similar. The School of Management at the UB had 140 members of academic, and administrative and other support staff, while the faculty of CEMS in the UWE had 132 members of academic staff, administrative and other support staff. ${ }^{2}$

In other words, if size is an important organisational variable, whether in extent of operations or number of employees, that affects the nature of business processes, these were two organisations which were roughly comparable.

\section{Processes and programme management}

A significant difference lay in the principles around which degree programmes were designed. While both institutions nominally divided their programmes up into modules, each with a credit value, the important academic decisions, which affected student progress and the awarding of credit, were made differently.

At the UB, credit was only awarded at the end of an academic year by the department which hosted the degree programme on which the student was registered: it was impossible to be awarded credit for individual modules under the normal regulations. Any student not meeting the criteria for passing a whole year was required to retake that year, including those modules which were passed the first time around. At the UWE, credit was awarded by the department that owned the module, so credit-awarding decisions for the same student could be taken in different departments. Students could, under this system, accumulate credits at a variable pace and, once a module was passed, it would never need to be retaken.

With other decisions affecting student progress there was a similar distinction. At the UB, decisions about whether or not a student was guilty of plagiarism, had a justified case for mitigating circumstances or for late submission of coursework, etc., were all taken by the department that ran the student's programme, even where these issues concerned modules owned by another department. At the UWE, all of these decisions were made by the department that owned the relevant module.

The difference in processes arose from the continued existence, in the UB, of the linear degree programme: there was a strong attachment to the idea of a student having to pass all elements of a traditional year-long, full time year of degree study in order to move on to the next. This was a model of academic progression which the UWE had moved away from since 1994. At the UWE, there was no distinction in the regulations between full and part time students, with no concept of them having to pass a whole year at a time. Degree programmes at the UWE were important because they identified students' areas of study, and this was recognised in the management of faculties. However, the award of credit was on a module-by-module basis: credit could be accumulated by students at different rates.

These differences were reflected in the contents of the respective quality documents. The UWE's modular assessment regulations included a series of job descriptions to demonstrate the responsibility of particular office-holders in a faculty, dean, award 
leader, field leader and module leader, for different stages of each procedure. This clear definition of responsibilities was less evident at the UB, where the code of practice was less prescriptive about the responsibilities of individuals: the only job titles to be mentioned were director of studies (the equivalent of award leader at the UWE) and head of department. Some areas of the management of programme quality, notably curriculum and module development were not allocated to particular managers.

In essence, what is evident here was a contrast between a more and less traditional approach to managing a university. The specification of particular jobs at the UWE was a defining characteristic of bureaucracies in the sense used in Weber's sociology of a regular, mechanistic structure (Ackroyd, 2002). The UB, by contrast, had a weaker formal definition of roles. The code of practice defined procedures and reporting requirements, but mentioned fewer formal roles. Most requirements within the procedures were linked to the programme leader (or 'director of studies') without a consideration of the boundaries of that role. Some procedures gave the director of studies responsibility for students, some for programmes, some for units and some for staff development. In practice, different departments were used to organising matters in their own way, a structure closer to what Mintzberg (1979) defined as professional bureaucracy: a large institution, but one in which individual employees have a considerable degree of autonomy in organising their working lives.

\section{Teaching and course development}

The UWE had a strongly modular programme. Each faculty was required to maintain a curriculum document, to which the fields in the faculty, i.e. subject groups, contributed modules. The construction of new degree programmes then became principally a matter of fitting together elements, often already in existence, from one or more fields. Like many of the pre-1992 universities, the UB's teaching programmes were based largely on distinct, linear degree programmes. Although units were defined as modules with set amounts of credit, degree programmes were designed and implemented as single entities.

At the UWE, modules were essentially 'owned' by the Fields. There was a clear line of responsibility for managing issues that arose in their staffing. The presumption was that, once a module had been offered, then it would run if enough students were taking it: staff illness meant that another member of staff had to step in. The removal of a module was a collective decision, the implications of which were discussed by the Field Committee, representing all staff members in the subject area.

At the UB, by contrast, most module development was left to the decisions of individual staff members. Where units were optional on a degree programme, they were often developed from the research of individual staff members, and so were not made available if that member of staff was unavailable for any reason, or left. The strong sense of personal ownership of modules was characteristic of the professional bureaucracy, and this affected the culture and the processes of the organisation. 


\section{Appendix 9}

Table A1 Glossary of abbreviations

\begin{tabular}{ll}
\hline CEMS & Computing, engineering and mathematical sciences \\
CMP & Case management process \\
CP & Case process \\
CSP & Case strategy process \\
DBE & Designed business entity \\
DUOW & Designed unit of work \\
EBE & Essential business entity \\
EUOW & Essential unit of work (AKA unit of work) \\
UB & University of Bath \\
UOW & Unit of Work \\
UWE & University of the West of England \\
\hline
\end{tabular}

\section{Notes}

1 To determine the particular content of a $\mathrm{CP}$, it is necessary to reflect upon the lifetime of the associated unit of work, an idea that seems similar to the entity life history concept from the structured systems analysis and design method SSADM: "Entity Life Histories document all of the events that can affect (i.e. cause a change to or constrain the life of) an entity" (Weaver et al., 2002).

2 These figures obtained at the time the process architecture analysis work presented in this paper was undertaken, i.e., 2006-2007. 